\title{
Analysis of lightning strokes associated with sprites observed by ISUAL in the vicinity of North America
}

\author{
Gaopeng Lu ${ }^{1,2,3,4, *}$, Steven A. Cummer ${ }^{5}$, Alfred B. Chen ${ }^{6}$, Fanchao Lyu ${ }^{5}$, Dongshuai Li ${ }^{7}$, Fei Liu ${ }^{7}$, \\ Rue-Ron $\mathrm{Hsu}^{6}$, and Han-Tzong $\mathrm{Su}^{6}$ \\ ${ }^{1}$ Key Laboratory of Middle Atmosphere and Global Environment Observation (LAGEO), Institute of Atmospheric Physics, \\ Chinese Academy of Sciences, Beijing, China \\ ${ }^{2}$ Key Laboratory of Meteorological Disaster of Ministry of Education, Nanjing University of Information Science and \\ Technology, Nanjing, Jiangsu, China \\ ${ }^{3}$ State Key Laboratory of Numerical Modeling for Atmospheric Sciences and Geophysical Fluid Dynamics (LASG), Institute of \\ Atmospheric Physics, Chinese Academy of Sciences, Beijing, China \\ ${ }^{4}$ Collaborative Innovation Center on Forecast and Evaluation of Meteorological Disasters, Nanjing Univ. of Information Science \\ and Technology, Nanjing, Jiangsu, China \\ ${ }^{5}$ Electrical and Computer Engineering Department, Duke University, Durham, North Carolina, USA \\ ${ }^{6}$ Department of Physics, National Cheng Kung University, Taiwan \\ ${ }^{7}$ Earth System Modeling Center and Climate Dynamics Research Center, Nanjing Univ. of Information Science and Technology, \\ Nanjing, China
}

\section{Article history:}

Received 29 February 2016

Revised 26 March 2017

Accepted 31 March 2017

\section{Keywords:}

Cloud-to-ground (CG) lightning stroke, Negative sprite, Space observation, Impulse charge moment change (iCMC)

\section{Citation:}

Lu, G., S. A. Cummer, A. B. Chen, F. Lyu, D. Li, F. Liu, R.-R. Hsu, and H.-T. Su, 2017: Analysis of lightning strokes associated with sprites observed by ISUAL in the vicinity of North America. Terr. Atmos. Ocean. Sci., 28, 583-595, doi: $10.3319 /$

TAO.2017.03.31.01

\begin{abstract}
We examined the broadband $(<1 \mathrm{~Hz}$ to $30 \mathrm{kHz})$ lightning sferics associated with 395 sprites observed near North America by the Imager of Sprites and Upper Atmospheric Lightning (ISUAL) onboard the FORMOSAT-2 satellite in a 12-year period from 2004 - 2015. Our analysis indicates that the ISUAL dataset contains a significant fraction $(69$, or $\sim 18 \%)$ of negative sprites, which were predominantly ( $>80 \%$ ) observed over oceanic and coastal thunderstorms mostly in tropical areas. The mean and median of impulse charge moment change (iCMC) associated with positive (negative) sprites are $+346 \mathrm{C} \mathrm{km}(-709 \mathrm{C} \mathrm{km})$ and $+280 \mathrm{C} \mathrm{km}(-649 \mathrm{C} \mathrm{km})$, respectively. The morphology and parent lightning properties (e.g., typically with high peak currents $>-80 \mathrm{kA}$ and large iCMCs $>-300 \mathrm{C} \mathrm{km}$ ) of negative sprites observed by the ISUAL are generally consistent with that documented in ground-based observations, but the ISUAL dataset does imply that sprites are sometimes produced by negative strokes with sub-critical iCMCs (less than $-300 \mathrm{C} \mathrm{km}$ ). Consequently, the future survey of global occurrence of sprites is desired to be based on complementary ground and space-borne observations.
\end{abstract}

\section{INTRODUCTION}

Red sprites, as one major type of lightning-induced transient luminous events (TLEs) above thunderstorms, are short-lived (typically $<20 \mathrm{~ms}$ ) structured optical emissions that could be observed from both ground-based (Franz et al. 1990; Boccippio et al. 1995; Lyons 1996; Yair et al. 2015) and space-borne platforms (Yair et al. 2004; Chen et al. 2008; Jehl et al. 2013; Sato et al. 2015). The broad

\footnotetext{
* Corresponding author

E-mail: gaopenglu@gmail.com
}

connection between sprites and energetic cloud-to-ground (CG) lightning strokes has been established by concurrent recording of distinct radio frequency electromagnetic pulses commonly registered upon the sprite observation (Reising et al. 1996; Cummer et al. 1998; Huang et al. 1999; Li et al. 2008; Lu et al. 2013). Sprite-producing CG strokes, which are usually characterized by the transfer of a large amount of electric charge from cloud to ground through impulse current (Gomes and Cooray 1998), are strong enough to excite Schumann resonance in the Earth-ionosphere waveguide 
(Huang et al. 1999). The global occurrence rate of sprites has thereby been estimated accordingly to be one event every two minutes on average (or 720 sprites day $^{-1}$ ) (Sato and Fukunishi 2003), which is in agreement with the long-term survey on a global scale based on the space-borne observations from the Imager of Sprites and Upper Atmospheric Lightning (ISUAL) aboard the FORMOSAT-2 satellite (Chen et al. 2008). In addition to sprites, ISUAL also provides a global observation of halos and elves as other two types of TLEs with shorter time scales (typically $<1 \mathrm{~ms}$ ) (Barrington-Leigh et al. 2001; Miyasato et al. 2002), and the evidence has been shown that both of them are associated with the more impulsive feature of causative CG strokes (Mende et al. 2005; Li et al. 2012; Williams et al. 2012).

For an improved understanding of global sprite occurrence with remote sensing of radio frequency lightning signals (sferics), it remains desirable to conduct a statistical analysis of sprite-related lightning properties based on a relatively large dataset with adequate time span and spatial coverage. In particular, the dataset should include a considerable amount of sprites observed over both continental and oceanic storms. Sprite observations from a space-borne platform in low-Earth orbit are most appropriate for this objective (e.g., Chen et al. 2008; Sato et al. 2015), whereas the lightning properties associated with sprites observed from space are rarely investigated on a statistical basis.

As the first space-borne platform that provides a longterm survey of sprite production on a global scale, ISUAL provides a unique opportunity to examine the lightning properties associated with sprites produced by oceanic thunderstorms (Chern et al. 2003). Here we focus on sprites observed by ISUAL in a 12-year period from July of 2004 to December of 2015. With broadband $(<1 \mathrm{~Hz}$ to $30 \mathrm{kHz})$ sferic data measured jointly with two sets of magnetic sensors deployed in Duke Forest $\left(35.971^{\circ} \mathrm{N},-79.094^{\circ} \mathrm{E}\right)$ near Duke University (e.g., Hu et al. 2002; Lu et al. 2009, 2013; $\mathrm{Li}$ et al. 2012), we analyzed the impulse charge moment change (iCMC, defined as the total charge moment change within $2 \mathrm{~ms}$ after the return stroke) and peak current of lightning strokes associated with a total of 395 sprites observed by ISUAL.

The observations and methods used in this work to quantitatively evaluate the electrical properties (e.g., peak currents and iCMCs) of ISUAL sprite-producing strokes are described in section 2. In section 3, we validated the geolocation accuracy of ISUAL relative to individual sprite observations, using the National Lightning Detection Network (NLDN) data for the parent strokes of ISUAL sprites within the detection range of NLDN (Cummins et al. 1998; Cummins and Murphy 2009). In addition, the NLDN provides an estimated peak current of sprite-producing strokes (e.g., Nag et al.2011), which can be used as a dataset for us to formulate an empirical approach to estimate the peak current of other sprite-producing strokes not detected by the NLDN. The dis- tribution of ISUAL sprites near North America produced respectively by positive and negative CG strokes is presented in section 4 , showing a considerable population of negative sprites over tropical oceans. In section 5 , we examine the peak currents and iCMCs of causative lightning strokes for ISUAL sprites on a statistical basis. In particular, we discuss the iCMCs of negative sprite-producing strokes, which are rarely documented in the continental thunderstorms (Lang et al. 2013) but constitute a significant fraction $(\sim 18 \%)$ of sprite observations in the ISUAL dataset. The main findings of this work are summarized in section 6 .

The results presented in this paper shed additional light on the paradox raised by Williams et al. (2007a) regarding the polarity asymmetry of sprite-producing lightning strokes. Their survey based on ground-based observations reported worldwide prior to 2005, including more than 3000 sprites documented in ground-based video imagery, indicates that the percentage of confirmative negative sprite observations is far below $1 \%$ (this ratio will increase to approximately $4 \%$ even those invalidated cases are included), which is inconsistent with the inferred proportion of negative sprites on the order of $10 \%$ from the Schumann resonance measurement (e.g., Hobara et al. 2006). This discrepancy constitutes a "sprite polarity paradox", which is attributed by Williams et al. (2012) to the idea that the vast majority of sprite-producible negative strokes generate halos instead (e.g., Hiraki 2010). Halos, with duration typically $\leq 2 \mathrm{~ms}$, are not readily captured by ground-based observations at regular speeds $\left(\sim 25\right.$ - 30 frames s$^{-1}$ ) (Wescott et al. 2001; Miyasato et al. 2002). Our analysis, however, suggests that negative sprites are significantly more frequent than one believed based on ground-based observations focused on continental thunderstorms, even though the occurrence of negative sprites requires a much higher iCMC for the parent stroke.

\section{OBSERVATIONS AND METHODS}

ISUAL makes an eastward limb observation from a polar, sun-synchronous orbit at $890 \mathrm{~km}$ altitude (the exact altitude of ISUAL varies slightly with latitude) (Chen et al. 2008). The scientific payload of ISUAL includes an image intensified CCD camera that records images at 100 frames s $\mathrm{s}^{-1}$ rate in the survey mode (Chern et al. 2003). In addition, ISUAL also acquires the multi-spectral photometric data and array photometric data with sub-millisecond resolution, making it possible to study the dynamics of sprite evolution (Kuo et al. 2005). Since July of 2004, ISUAL has recorded near 40000 transient luminous events (TLEs) by the end of 2015, including about 2600 sprites. Some of these sprites were accompanied by halos (about on third) and elves $(\sim 15 \%)$, which are not investigated in this paper.

Throughout this paper, we use the Coordinated Universal Time (UTC), and the altitude (in $\mathrm{km}$ ) is relative to the mean sea level (MSL). The sign convention of lightning 
polarity is that a positive (negative) stroke transfers positive (negative) charge from cloud to ground.

For the majority of ISUAL sprites, broadband radio frequency data were recorded in Duke Forest with relatively low background noise, which include the broadband $(<1 \mathrm{~Hz}$ to $400 \mathrm{~Hz}$ ) down to ultra low-frequency (ULF) and very low-frequency (VLF, $50 \mathrm{~Hz}$ to $30 \mathrm{kHz}$ ) magnetic fields that are sampled at 2.5 and $100 \mathrm{kHz}$, respectively. To ensure a quantitative analysis with reliable sferic measurements and the estimation of lightning peak current and $\mathrm{iCMC}$, we focus the analysis on ISUAL sprites with reported location in the geographic domain $\left(0-50^{\circ} \mathrm{N}\right.$, and $50^{\circ}-150^{\circ} \mathrm{W}$ ) shown in Fig. 1. ISUAL observed a total of 422 sprites in this region during 2004 - 2015, and the vast majority ( $>95 \%$ ) of these sprites were observed during four 30-min time intervals centered at 03:00 UTC, 04:40 UTC, 06:25 UTC, and 08:10 UTC, respectively. Some events that remain questionable on the classification or do not have the concurrent sferic measurements are not examined, leaving a total of 395 ISUAL sprites that constitute the main dataset for our further analysis using validated sferic data (Table 1). For most sprites, we compute the associated iCMCs with the ULF data using the approach developed by Cummer and Inan (2000), which has been adopted extensively in our previous work (Hu et al. 2002; Cummer and Lyons 2005; Lu et al. 2012, 2013); when the ULF data are not available for an event, the low-pass filtered VLF data are used to estimate the iCMC (e.g., Li et al. 2012).

As shown in Fig. 1, the dataset examined in this paper contains a significant fraction (approximately 54\%) of sprites observed over oceans, including many sprites far beyond the detection range of ground-based observations. As discussed by Chen et al. (2008), the U.S. High Plains as one of the well known hot zones for sprite production (e.g., Boccippio et al. 1995; Lyons 1996) is in the ISUAL coverage with small accumulative observation time (because the payload is turned off before exiting the Earth's umbra around $25^{\circ} \mathrm{N}$ during the northern hemisphere summer to protect equipments from direct sunlight) (Fig. 2, Chen et al. 2008). Most sprites observed by the ISUAL in the continental United States are over the eastern states during the Northern summer.

Figures $2 \mathrm{a}$ and $\mathrm{c}$ show the broadband lightning signals for two selected ISUAL sprites (Figs. $2 b$ and $d$ ) that were produced by a positive and a negative CG stroke, respectively. Some important features present in the sferics that are used in our analysis are indicated. The leading fast pulse with a distinct oscillatory feature (e.g., Dowden et al. 2002, Fig. 2) is driven by the initial contact (i.e., return stroke) of a lightning stroke and can be used to estimate the peak current (Pessi et al. 2009; Nag et al. 2011). The trailing slow pulse with timescale longer than $1 \mathrm{~ms}$ is excited by the subsequent impulse current (Gomes and Cooray 1998), which makes the major contribution to the charge moment change
(iCMC) within $2 \mathrm{~ms}$ after the return stroke by removing electric charge from the existing lightning channels ( $\mathrm{Lu}$ et al. 2009). In this paper, the polarity of sprite-producing strokes is determined through the polarity of magnetic pulse from an impulse current; in the cylindrical coordinate system with the lightning stroke at the origin, the impulse current in positive (negative) strokes will radiate a negative (positive) magnetic pulse (e.g., Lu et al. 2012; Li et al. 2012).

For both sprites shown in Fig. 2, the halo feature is discernible, and the signal of impulse lightning current is distinct but with different timescales; the impulse current of negative sprite-producing strokes is usually more impulsive than that of positive sprite-producing strokes (e.g., Li et al. 2012; Williams et al. 2012). As shown in Fig. 2a, the sferic signal for the positive sprite also contains a second slow pulse that could be unambiguously identified due to the lack of higher frequency $(>1 \mathrm{kHz})$ radiation (e.g., Stanley et al. 2000; Füllekrug et al. 2001; Hu et al. 2002; Lu et al. 2013), which is attributed to the current flow along sprite bodies (Cummer et al. 1998; Pasko et al. 1998). By examining sprite-associated sferics with distinct sprite current signal, we found that a discernible sprite current signal, not surprisingly, are unique to those sprites that appeared bright (with a relatively large vertical scale). In particular, one convenient criterion is the presence of multiple visible downward streamers, which are of positive polarity for sprites produced by positive CG strokes. The positive iCMCs greater than $+1000 \mathrm{C} \mathrm{km}$ almost certainly include a considerable contribution from the sprite current, whereas we do not distinguish further in the associated analysis. For the case of a negative sprite (Fig. 2c), a similar feature is also evident in the VLF sferics, but the comparison with photometric data indicates that this secondary pulse is not linked to a sprite current. It is more likely associated with the propagation effect of lightning signals in the Earth-ionosphere waveguide (Cummer and Inan 2000).

The parent strokes were detected by NLDN for 114 ISUAL sprites with typical location accuracy better than $1 \mathrm{~km}$ (Cummins et al. 1998; Biagi et al. 2007), and these events constitute a valuable dataset to formulate an approach to estimate the peak currents of sprite-producing strokes beyond the detection range of NLDN. In order to estimate the peak current of sprite-producing strokes from the VLF sferics (e.g., Nag et al. 2011), we use an empirical relationship previously used by Lu et al. (2011) as follows,

$B_{\max }=\alpha \cdot I_{p k} / r^{\beta}$

where $r(\mathrm{~km})$ is the distance from lightning source to the sensor, $B_{\max }(\mathrm{nT})$ is the peak amplitude of VLF sferics, and $I_{p k}(\mathrm{kA})$ is the estimated peak current. The values of two unknown parameters in Eq. (1), $\alpha$ and $\beta$, depend on the time of observation (i.e., daytime or nighttime) (Lu et al. 2011). 


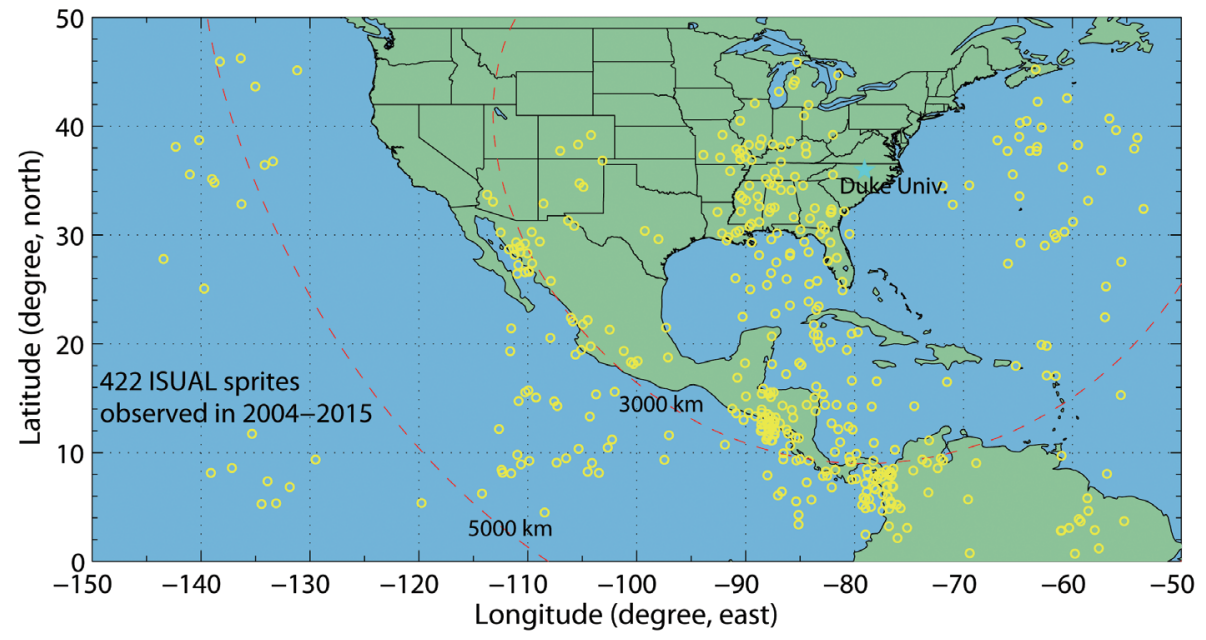

Fig. 1. Sprites observed by ISUAL in the vicinity of North America in 2004 - 2015 (sprites are indicated by yellow circles, and the measurement site near Duke University is indicated by a cyan star). Most sprites observed by ISUAL in the continental United States are over the eastern states during the northern hemisphere summer. (Color online only)

Table 1. Overview of ISUAL sprite observations examined in this work. The positive and negative sprites are further categorized to events over continent and ocean according to the location reported by the ISUAL.

\begin{tabular}{cc}
\hline Category for ISUAL sprites observed in 2004 - 2015 & Number of events \\
\hline Total ISUAL sprites in the selected geographic region & 422 \\
Events with ULF/VLF data for estimating iCMC & 395 \\
Events associated with NLDN stroke data & 114 \\
Events with VLF data for estimating peak current (or with peak current estimated by the NLDN) & 247 \\
Positive sprites (land/ocean) & $326(166 / 160)$ \\
Negative sprites (land/ocean) & $69(16 / 53)$ \\
\hline
\end{tabular}

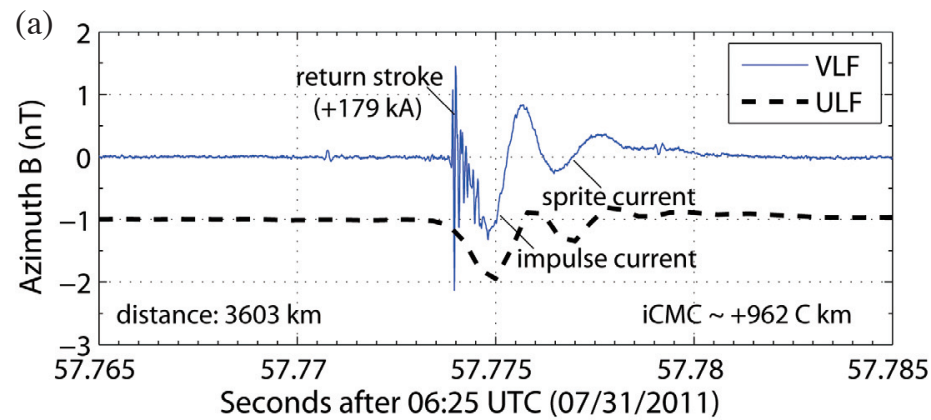

(b)

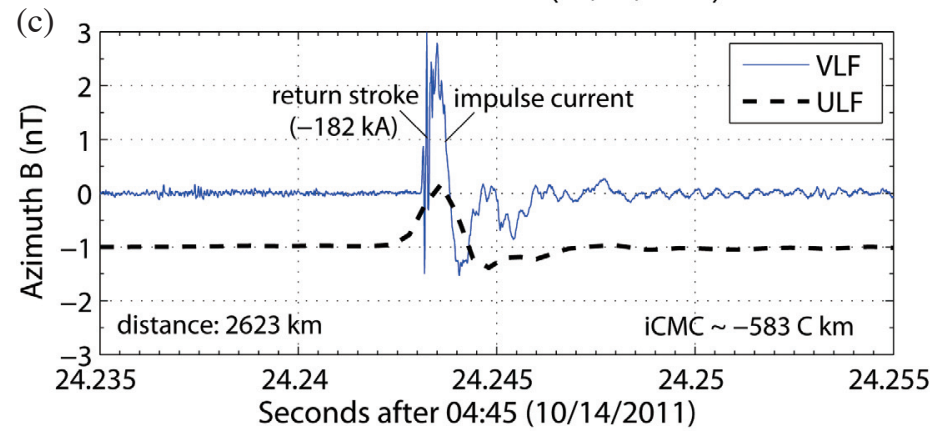

(d)

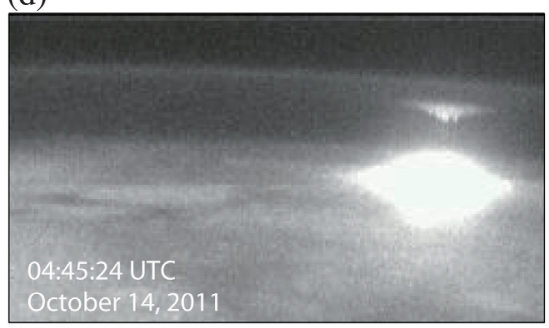

Fig. 2. Broadband (VLF: $50 \mathrm{~Hz}$ to $30 \mathrm{kHz}$; ULF: < $1 \mathrm{~Hz}$ to $400 \mathrm{~Hz}$ ) magnetic lightning sferics [(a) and (c)] recorded in Duke Forest in association with a positive sprite (b) and a negative sprite (d) observed by ISUAL on 31 July 2011 and 14 October 2011, respectively. The halo feature is clear for both cases, while the elve is only barely discernible for the positive sprite shown in (b). (Color online only) 
With relevant data for 68 parent strokes of ISUAL sprites that were detected by the NLDN at nighttime and for which the VLF measurements are also available, we applied the least-squared method to obtain $\alpha=48.01$ and $\beta=1.014$, which is consistent with the estimation of $\mathrm{Lu}$ et al. (2011) for the nighttime case. As shown in Fig. 3, using Eq. (1), the peak current can be estimated with 50\% uncertainty. This empirical method is therefore applied to estimate the peak current for other parent strokes of ISUAL sprites not registered by NLDN but with VLF sferic signals available; it is assumed the stroke is located at the ground projection of an ISUAL-reported sprite. For the two sprite-producing strokes shown in Figs. $2 \mathrm{~b}$ and $\mathrm{d}$, the peak current is estimated to be +179 and $-182 \mathrm{kA}$, respectively, and the iCMC is calculated to be +962 and $-583 \mathrm{C} \mathrm{km}$, respectively. In section 3, we will show that the sprite location determined by ISUAL is generally consistent with parent strokes with spatial displacement $<100 \mathrm{~km}$, which will not affect the main conclusions presented in this paper.

\section{ACCURACY OF SPRITE LOCATION INFERRED FROM ISUAL OBSERVATION}

ISUAL observes TLEs near the Earth's limb typically at range of $2300-4000 \mathrm{~km}$ from the carrier satellite (Chen et al.2008), and it is of our particular interest how accurate a sprite event can be located with the observation from space. As shown in Fig. 1, many ISUAL sprites were observed over the continental United States, and the causative strokes were in the detection range of NLDN, which locates lightning discharges with uncertainty typically $<1 \mathrm{~km}$ (Biagi et al. 2007; Nag et al. 2011). This provides an opportunity to evaluate the accuracy of sprite location inferred from spaceborne platforms since sprites are typically centered within $50 \mathrm{~km}$ of the parent strokes according to the triangulation from ground-based observations at different locations (Lyons 1996; Füllekrug et al. 2001; Lu et al. 2013).

With the NLDN data accessible, we identified 114 lightning strokes as the parent CGs of ISUAL sprites, including 33 events located in the oceans. Figure 4a shows the ground location of these strokes (red triangles) in comparison with the sprite location (blue circles) inferred from ISUAL observation; Fig. 4b shows the ISUAL-inferred sprite location (blue ' + 's) relative to the causative stroke. As ISUAL makes an eastward limb-viewing observation, the error of sprite location is mainly in the longitudinal direction; the geolocation error in the latitudinal direction is usually $<100 \mathrm{~km}$. The comparison shown in Fig. 4b indicates that the sprite location inferred from ISUAL observation is typically within $100 \mathrm{~km}$ laterally displaced from the parent stroke, which validates the procedure applied to the ISUAL images (Chen et al. 2008) to determine the geographic location of sprites. For 85 ISUAL sprites $(\sim 75 \%)$ associated with NLDN strokes, the ISUALreported locations are within $50 \mathrm{~km}$ of the parent stroke.

The examination of ISUAL images further suggests that the sprites with inferred location $>100 \mathrm{~km}$ from the parent strokes were usually caused by that the illuminated cloud top behind the horizon (and thus not in sight) was treated erroneously as a visible case in the data analysis (Chen et al. 2008). For example, the largest location error $(\sim 1400 \mathrm{~km})$ is for an extraordinarily bright sprite at 06:32:53 UTC on 20 March 2012, which was associated with a large iCMC of $+1025 \mathrm{C} \mathrm{km}$. As shown in the inset of Fig. 4a, the diffuse top of this sprite likely extended above $90 \mathrm{~km}$ (e.g., Pasko and Stenbaek-Nielsen 2002), and the streamer region of this sprite extended downward almost to the barely visible cloud top in the ISUAL image, indicating that the parent thunderstorm itself was located beyond the horizon (i.e., the storm itself is actually not in sight); in this situation, the top of sprites (at $85-90 \mathrm{~km}$ ) should have been used to derive the

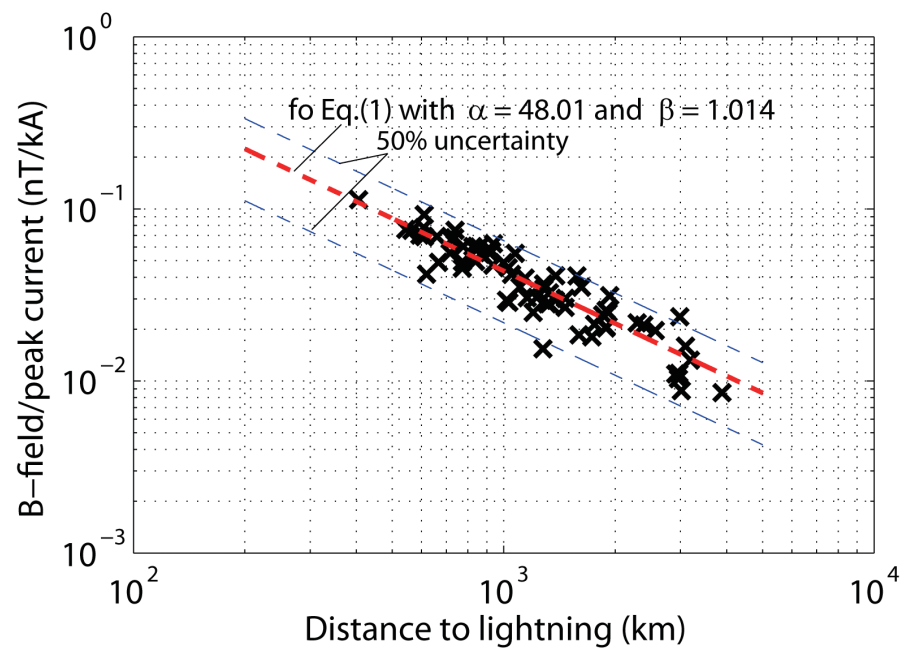

Fig. 3. Least-squared determination of parameters in Eq. (1) to estimate the peak current of sprite-producing strokes from VLF sferics. The training dataset contains 68 ISUAL sprite-producing CG strokes detected by NLDN for which the VLF measurement is also available. (Color online only) 

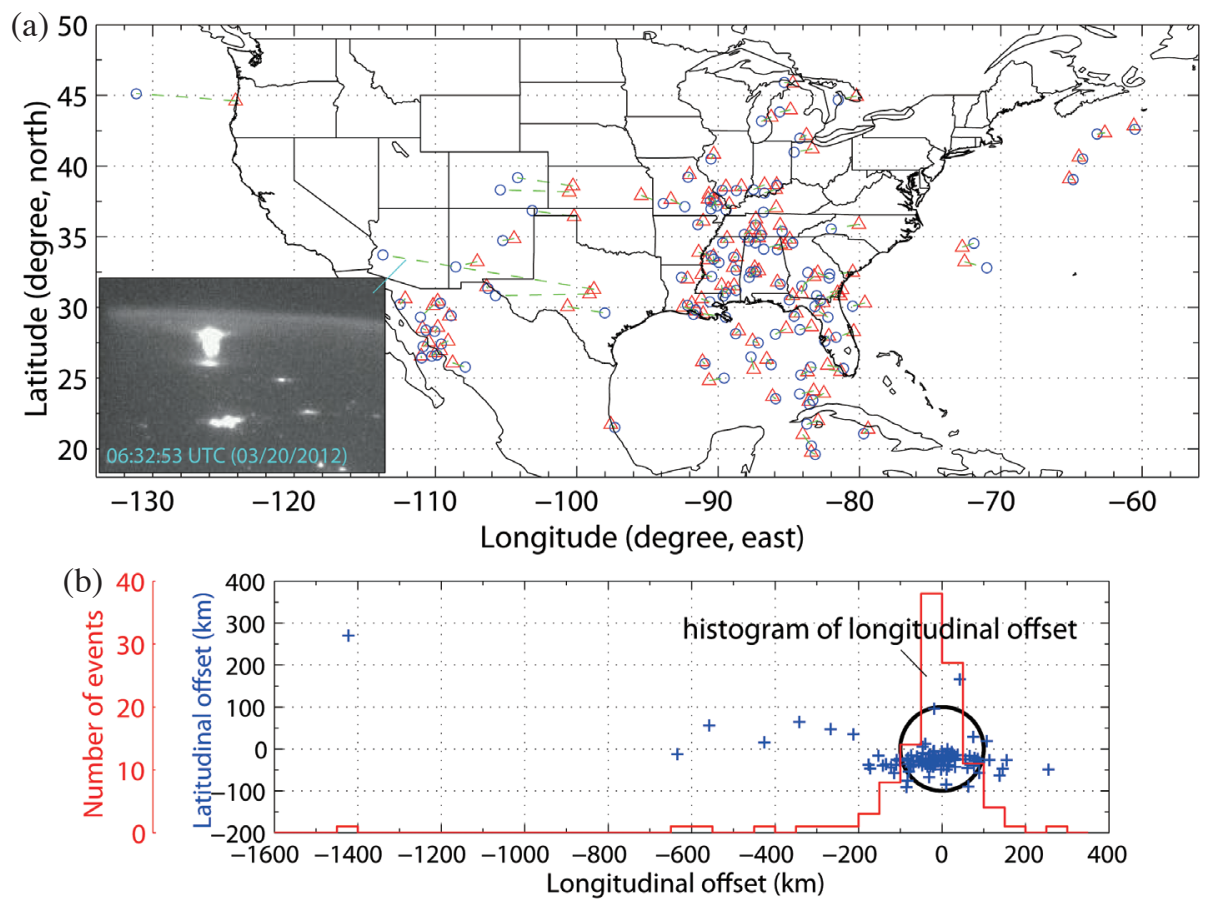

Fig. 4. (a) Comparison between ISUAL-reported locations of 114 sprites (blue circles) and locations of parent strokes (red triangles) registered by the National Lightning Detection Network (NLDN). (b) ISUAL-determined sprite location relative to the parent ground stroke, indicating that ISUAL usually locates the parent stroke of sprites with uncertainty (mainly in the longitudinal direction for most cases) less than $100 \mathrm{~km}$. The relatively large location error $(>200 \mathrm{~km})$ is usually caused by treating the sprite-producing thunderstorm behind the horizon (and thus not in sight) erroneously as a visible case (e.g., Chen et al. 2008). (Color online only)

location. However, the current procedure of analysis will treat this situation as a case where the thunderstorm is in front of the horizon (i.e., the storm is visible or in sight) (e.g., Chen et al. 2008), leading to considerable error in the sprite location. Nevertheless, the sprite geolocation reported by ISUAL can be used as an estimate of parent strokes beyond the detection range of NLDN, and the uncertainty in the iCMC estimate due to the uncertainty in stroke locations is less than $10 \%$.

\section{ISUAL SPRITES PRODUCED BY POSITIVE AND NEGATIVE CG STROKES}

With broadband lightning sferics recorded in Duke Forest, we estimate the iCMCs for a total of 395 ISUAL sprites. Figure 5 shows the spatial distribution of ISUAL sprites produced by positive and negative CG strokes that are shown as red and blue open circles, respectively. The area of each circle is proportional to the magnitude of iCMCs estimated from the sferics data. For the ISUAL sprites with lateral displacement $>200 \mathrm{~km}$ from the parent strokes as detected by NLDN, we place the sprites at the reported location of parent strokes.

Not surprisingly, as listed in Table 1, the majority of sprites ( 326 out of 395 , about $82.5 \%$, with about half in the oceans) observed by the ISUAL were produced by $+\mathrm{CG}$ strokes, which is especially distinct in the continental region. As shown in Fig. 5, almost all the sprites observed by the ISUAL in the continental United States and oceans at relatively high latitudes (to the north of $35^{\circ} \mathrm{N}$ ) are produced by positive CG strokes (e.g., Williams et al. 2012).

Our results shown in Fig. 5 indicate that there is a considerable population of sprites associated with negative strokes in the ISUAL dataset. About $17.5 \%$ (69 out of 395) of ISUAL sprites examined in this work were produced by negative CG strokes, the majority (53 out of $69, \sim 77 \%$ ) of which were observed over oceanic regions at relatively low latitudes (to the south of $35^{\circ} \mathrm{N}$ ); the halo feature (and sometimes elves as well) is discernible for almost all of these 69 negative sprites (with only one exception associated with a small iCMC below $-100 \mathrm{C} \mathrm{km}$; see Table 2 and associated discussions), which is in excellent agreement with previous reports (Taylor et al. 2008; Li et al. 2012). Also, all negative sprites are prompt events that occurred within $10 \mathrm{~ms}$ after the parent return stroke. In particular, the negative sprites appear to dominate in a broad area of the Caribbean Sea. Therefore, the sparsity of negative sprites in ground-based observations is likely a consequence of different capability of continental and oceanic/coastal thunderstorms in spawning negative CG strokes with sprite-producible iCMCs (e.g., Füllekrug et al. 2002). As shown in Fig. 5, many negative sprites observed by the ISUAL over the Caribbean Sea are 


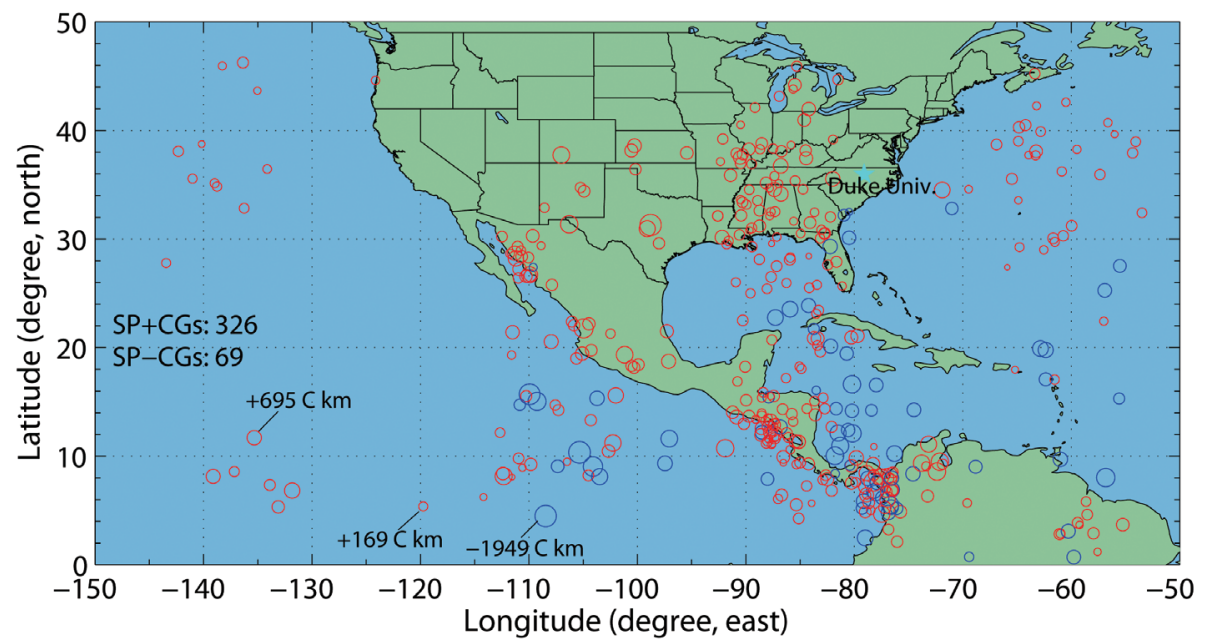

Fig. 5. Distribution of sprites near North America observed by ISUAL in 2004 - 2015. The area of circles (red for positive sprites and blue for negative sprites) is proportional to the magnitude of iCMCs. For sprites with lateral displacement $>200 \mathrm{~km}$ from the parent strokes, the sprites are placed at the causative stroke location. (Color online only)

Table 2. List of sprites observed by the ISUAL in association with negative iCMC less than $-300 \mathrm{C} \mathrm{km}$.

\begin{tabular}{cccc}
\hline Time of ISUAL event & Location & iCMC & $\boldsymbol{I}_{\text {peak }}$ \\
\hline 08/24/2005 04:43:28.021 UTC & $\left(32.5^{\circ} \mathrm{N},-80.48^{\circ} \mathrm{E}\right)$ & $-65 \mathrm{C} \mathrm{km}$ & $-75 \mathrm{kA}$ \\
07/10/2007 04:51:37.397 UTC & $\left(9.16^{\circ} \mathrm{N},-80.43^{\circ} \mathrm{E}\right)$ & $-247 \mathrm{C} \mathrm{km}$ & N.A. \\
08/27/2009 04:27:52.365 UTC & $\left(16.07^{\circ} \mathrm{N},-83.51^{\circ} \mathrm{E}\right)$ & $-129 \mathrm{C} \mathrm{km}$ & N.A. \\
09/24/2013 04:38:22.126 UTC & $\left(8.41^{\circ} \mathrm{N},-81.76^{\circ} \mathrm{E}\right)$ & $-151 \mathrm{C} \mathrm{km}$ & N.A. \\
03/13/2014 04:39:43.589 UTC & $\left(0.74^{\circ} \mathrm{N},-69.42^{\circ} \mathrm{E}\right)$ & $-200 \mathrm{C} \mathrm{km}$ & N.A. \\
$08 / 30 / 201406: 37: 35.221 \mathrm{UTC}$ & $\left(27.4^{\circ} \mathrm{N},-109.6^{\circ} \mathrm{E}\right)$ & $-115 \mathrm{C} \mathrm{km}$ & $-75 \mathrm{kA}$ \\
\hline
\end{tabular}

also within the detection range of low-light-level observations from the nearby coast, and thus it is feasible to verify the dominance of negative sprites in this region through ground-based observations. Meanwhile, it is desirable to carry out similar survey in other regions, especially the East and South China Sea as known hot zones for sprites (Su et al. 2002; Chen et al. 2008).

The so-called "sprite polarity paradox" could also be explained by the asymmetry for the ambient electric field required by the propagation of negative and positive streamers (Qin et al. 2011, 2013) and also by the continental bias of previous ground-based sprite observations (Lyons 1996; Cummer and Lyons 2004; Williams et al. 2012). Sprites essentially contain a number of streamers that extend downward in an external electric field exceeding a critical value, which is higher by a factor of $\sim 3$ for positive streamers (as in negative sprites) than for negative streamers (as in positive sprites) (e.g., Pasko et al. 2000; Qin et al. 2011). Consequently, the occurrence of negative sprites usually requires a larger charge moment change than their positive counterparts. Through the numerical simulations based on the conventional breakdown mechanism, Qin et al. (2013) derived the critical charge moment change for the production of positive and negative sprites to be typically +320 and $-500 \mathrm{C} \mathrm{km}$, respectively; under favorable ionospheric conditions (e.g., inhomogeneities and relatively high reference altitude of ionosphere), this threshold could drop to +200 and $-320 \mathrm{C} \mathrm{km}$, respectively (Qin et al. 2012). The Schumann Resonance method does not have adequate temporal resolution to differentiate the contribution from impulse charge transfer and long continuing current (e.g., Huang et al. 1999; Williams et al. 2007b). Therefore, it is necessary to analyze the electrical properties (especially charge moment changes) of sprite-producing strokes with a better temporal resolution on a statistical basis.

\section{ELECTRICAL PROPERTIES OF ISUAL SPRITE-PRODUCING STROKES}

In this section, we examined the electrical properties (i.e., peak current $I_{p k}$ and impulse charge moment change, iCMC) of parent strokes for the ISUAL sprites. The iCMC 
was introduced by $\mathrm{Hu}$ et al. (2002) as a convenient and effective proxy to evaluate the potential of a specific lightning stroke for sprite production (e.g., Cummer and Lyons 2004; Cummer et al. 2013), although it does not necessarily represent the exact strength of lightning charge transfer (which exhibits variance due to the variability of nighttime mesospheric conductivity) responsible for triggering sprites (Cummer and Lyons 2005; Qin et al. 2013). For instance, for a mesoscale convective system (MCS) in central United States that produced about 70 sprites, the positive CG strokes with iCMCs larger than $+200 \mathrm{C} \mathrm{km}$ are $75 \%$ likely to produce sprites (and the likelihood increases to near 95\% for iCMCs $>+400 \mathrm{C} \mathrm{km}$ ) (Lu et al. 2013). In contrast, the peak current of lightning return strokes, which is a metric of lightning strength provided by normal lightning detection networks and is commonly used for measuring potential lightning hazard in lightning protection (Cummins et al. 1998; Cummins and Murphy 2009), is not ideal for predicting the likelihood of sprite production. This assertion is especially true for negative CG strokes (Lu et al. 2012).

The scatter plot in Fig. 6a shows the iCMC and peak current for individual lightning strokes associated with 247 ISUAL sprites, including 209 positive strokes (SP + CGs) and 38 negative strokes (SP - CGs). Generally speaking, there is not an especially well defined correlation between iCMC and peak current (Lu et al. 2012) except for that the strokes with higher peak currents can produce iCMCs in a broader range, and can cause a larger maximum iCMC. We also followed the method of Cummer et al. (2013) to examine the correlation between peak current and mean iCMC by appropriately binning the strokes according to peak current; the average peak current and mean iCMC are calculated for each bin. As shown in Fig. 6a, there is a general trend that the mean iCMC increases with peak current (e.g., up to about $\pm 200 \mathrm{kA}$ ), with a linear scaling factor of $\sim 3$ for positive strokes and $\sim 4$ for negative strokes.

Figure $6 \mathrm{~b}$ shows the histogram of ratio between iCMC and peak current for individual sprite-producing strokes, showing that this ratio typically (for $\sim 76.5 \%$ of the cases) varies in the range of 1 to 5 . The mean (median) iCMC-to$I_{p k}$ ratio for all the strokes is 3.50 (3.16); for positive and negative strokes, the mean (median) iCMC-to- $I_{p k}$ ratio is 3.51 (3.09) and 3.77 (3.45), respectively. The results are not considerably changed if the sprite-associated iCMCs greater than $\pm 1000 \mathrm{C} \mathrm{km}$ (which very likely contain the contribution from sprite current) are excluded from the analysis. This implies that the charge moment change associated with sprite current (in relatively bright sprite events) probably does not contribute considerably to iCMC calculated in this paper (Cummer et al. 1998; Hu et al. 2002).

\section{1 iCMCs of Sprite-Producing Strokes}

Figure 7a shows the histogram of iCMCs for positive and negative CG strokes associated with ISUAL sprites, showing a log-normal distribution (which is especially clear for positive sprites). The mean and median iCMC of positive causative strokes for 326 sprites observed by ISUAL is +346 and $+280 \mathrm{C} \mathrm{km}$, respectively; in contrast, the mean and medium iCMCs associated with 69 ISUAL-registered negative sprites are -709 and $-649 \mathrm{C} \mathrm{km}$, respectively, which are not significantly different from the average iCMC $(-739 \mathrm{C} \mathrm{km})$ for a total of eleven negative sprites examined by Li et al. (2012) and Boggs et al. (2016). Therefore, the threshold for negative sprites is substantially higher (by a factor of 2) than that for positive sprites, which is consistent with the idea that the threshold for propagation of negative streamers is much higher than that for positive streamers (e.g., Qin et al. 2011). In Fig. 7b, the cumulative distribution of sprite-associated iCMCs shows the proportion of spriteproducing strokes (relative to the entire dataset and respective polarity) with iCMCs greater than a certain value. The polarity-specific curves more clearly show the asymmetric distribution of iCMCs for positive and negative sprite-producing strokes. For example, for the level below which the iCMCs account for $\sim 80 \%$, it is around +450 and $-900 \mathrm{C} \mathrm{km}$ for positive strokes and negative strokes, respectively.

For the 16 negative sprites observed over continent, the mean iCMC is $-563 \mathrm{C} \mathrm{km}$, which is considerable smaller than that $(-753 \mathrm{C} \mathrm{km})$ for the 53 negative sprites over oceans. Therefore, our results reported here suggest that the occurrence of negative sprite might require a larger threshold over the ocean, which merits further investigation in the ground-based observations of negative sprites.

The statistics of iCMCs associated with ISUAL sprites shown in Fig. 7 remain useful to assess the global occurrence of sprites based on iCMC measurements. The iCMCs calculated for individual sprite-producing strokes are only part of the charge moment change responsible for initiating mesospheric breakdown, and the exact threshold for the sprite production ranges from +350 to $+600 \mathrm{C} \mathrm{km}$ depending on the type of thunderstorm (Cummer and Lyons 2005; Hiraki and Fukunishi 2006). However, iCMCs have been validated to predict the occurrence of sprites with good consistency. For example, the study of sprite-producing strokes generated by an MCS in central United States indicates that the CG strokes with iCMCs $>+300 \mathrm{C} \mathrm{km}$ are more than $80 \%$ likely to produce sprites (Lu et al. 2013). More similar analyses on a thunderstorm basis (for various types of thunderstorms, such as MCSs, supercells, and tropical cyclones) will lead to a statistically important threshold in term of iCMCs for the sprite production. By presuming that the lightning iCMCs exhibit the same distribution pattern, we can estimate the portion of sprite-producible strokes from the overall iCMC distribution for all the lightning strokes detected by the network. Of course, the result will be considerably affected by the detection efficiency of ISUAL with respect to sprites. ISUAL records data for an event when 

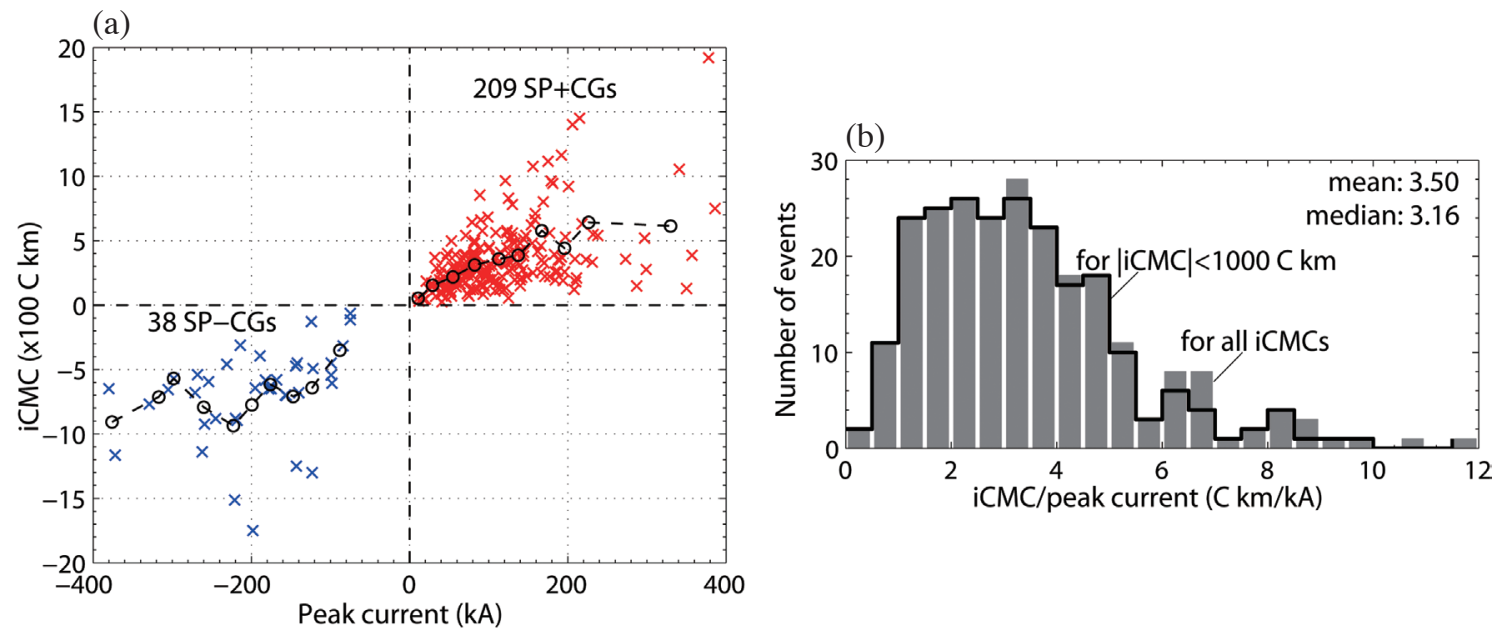

Fig. 6. (a) Scatter plot showing the impulse charge moment change (iCMC) and peak current for 247 strokes associated with ISUAL sprites. (b) Histogram of ratio between iCMC and peak current for the sprite-producing strokes. (Color online only)
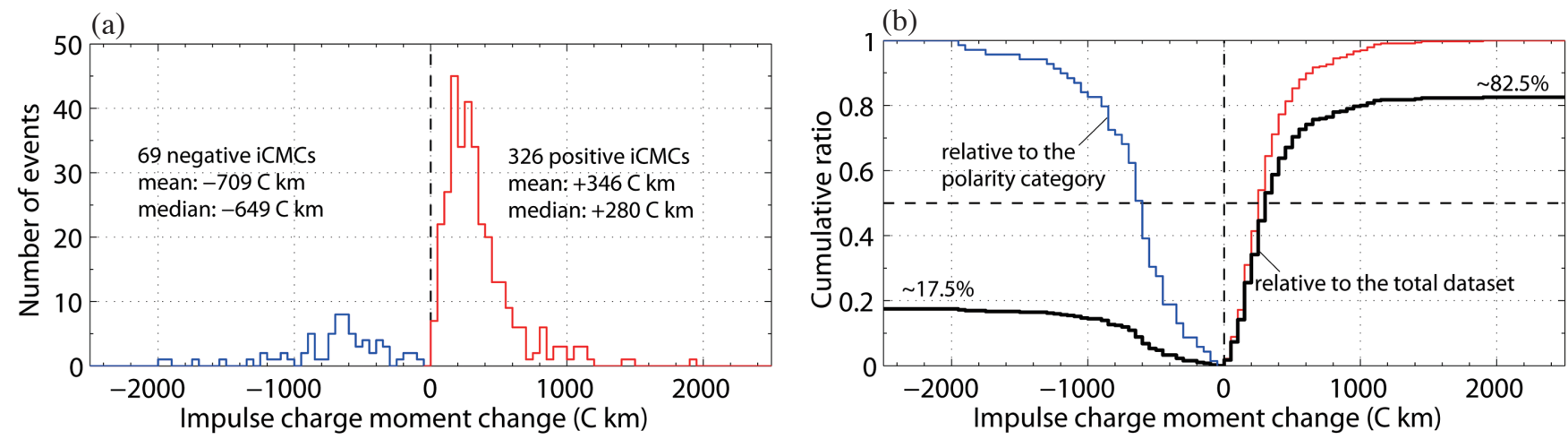

Fig. 7. Statistics of impulse charge moment changes (iCMCs) associated with 395 sprites (including 326 positive events and 69 negative events) observed by ISUAL over North America in 2004 - 2015: (a) histogram of iCMCs in $50 \mathrm{C}-\mathrm{km}$ bin; and (b) cumulative ratio (relative to the total dataset and strokes of each polarity, respectively) of sprite-associated iCMCs, showing an asymmetric distribution of iCMCs for positive and negative strokes. (Color online only)

the six-channel spectrophotometer is triggered. Due to the limited onboard memory and bandwidth of data transfer to ground, the trigger level was set empirically to maximize the TLE detection (Chen et al. 2008). It has been shown that the lightning luminosity is typically proportional to the magnitude of impulse charge transfer in lightning strokes (Adachi et al. 2009), and thus the ISUAL might miss some relatively dim sprites typically associated with small iCMCs. For example, it is likely the ISUAL is not triggered by many lightning events (mostly of positive polarity) that produce columnar sprites, which are readily to observe from ground stations under favorable conditions. The columnar sprites are rare in the dataset examined in this paper. The ISUAL should have a better performance on the observation of negative sprites, which are usually bright. Nevertheless, it is possible that the predominance of elves in TLEs on a global scale as concluded by Chen et al. (2008) might be slightly overestimated.

The ground-based observations of nine confirmed negative sprites have consistently indicated that the negative sprite-producing CG strokes produced iCMCs at least -450 C km (Barrington-Leigh et al. 1999; Taylor et al. 2008; $\mathrm{Li}$ et al. 2012). Our analysis based on a much larger dataset from ISUAL observations indicates that a small fraction (6 out of 69 , about $9 \%$ ) of negative sprites can be produced by negative CG strokes with iCMC less than $-300 \mathrm{C} \mathrm{km}$ (as small as $-65 \mathrm{C} \mathrm{km}$ ). Therefore, there might be some situations where the sprite can be produced with even smaller negative iCMCs. For the six negative sprites related to iCMCs less than $-300 \mathrm{C} \mathrm{km}$, almost all of them are very dim. These events will be further examined in the future to get more insights into the ambient conditions that could be favorable for the occurrence of mesospheric breakdown associated with sub-critical iCMCs. 


\subsection{Peak Currents of Sprite-Producing Strokes}

For a total of 247 ISUAL sprites, the peak current of causative strokes is provided by the NLDN (for 68 cases) or can be estimated from the Duke VLF sferics with $50 \%$ uncertainty (for 179 cases) using the empirical relationship described in section 2. Figure 8 shows the histogram of peak currents for these sprites, including 38 negative strokes and 209 positive strokes. Generally speaking, the negative CG strokes associated with ISUAL sprites tend to have higher peak current (with mean and median of -195 and $-185 \mathrm{kA}$, respectively) than positive strokes (with mean and median of +115 and $+97 \mathrm{kA}$, respectively), which is consistent with the findings from ground-based observations (e.g., Li et al. 2012; Lu et al. 2013; Boggs et al. 2016). For eight negative sprite-producing strokes over oceans, the mean peak current is $-169 \mathrm{kA}$, considerably smaller than that $(-202 \mathrm{kA})$ for the 30 negative strokes over ocean. As shown in the figure, the peak current of positive causative CG strokes of ISUAL sprites could be below $+20 \mathrm{kA}$. The ground-based observations indicate that small peak currents could also be associated with prompt sprites that are produced within $20 \mathrm{~ms}$ after the return stroke (Lu et al. 2013), likely due to the presence of a sufficiently strong short-delayed continuing current (Reising et al. 1996).

For negative causative CG strokes of ISUAL sprites, however, the peak current is usually high, and the lowest peak current for negative sprite-producing stroke is $-75 \mathrm{kA}$ (in two cases, and the associated iCMC is -65 and $-115 \mathrm{C} \mathrm{km}$, respectively). This validates our previous work that selected negative CG strokes with peak current in excess of $-80 \mathrm{kA}$ as the candidate sprite producers ( $\mathrm{Lu}$ et al. 2012). The minimum peak current associated with negative sprites reported in the literature was -93 kA (Barrington-Leigh et al. 1999; Li et al. 2012; Boggs et al. 2016), and the mean value is $-153 \mathrm{kA}$ (compared to $-195 \mathrm{kA}$ in our analysis). Therefore, although the peak current is not an ideal proxy to determine the potential for a specific stroke to produce mesospheric breakdown, it can be at least used as an initial criterion to sort out the negative strokes with higher chance to produce sprites. For negative CG strokes, the sprite production is predominantly produced through the impulse charge transfer within several milliseconds after the return stroke (Li et al. 2012; Boggs et al. 2016; Lu et al. 2016), and the contribution of long continuing current (if present) is usually negligible.

\section{SUMMARY}

In this paper, we examined the impulse charge transfer of parent strokes for a total of 395 sprites observed by the ISUAL from space with simultaneous broadband lightning signals recorded near Duke University in 2004 - 2015. The majority of sprites were produced by positive CG strokes, while the ISUAL dataset contains a significant fraction
( $18 \%)$ of sprites (almost all with halo) associated with negative CG strokes. Despite the few negative sprites reported in the literature, the vast majority $(>80 \%)$ of negative parent strokes of sprites observed by ISUAL are generated by oceanic/coastal thunderstorms, which is interpreted as a possible resolution to the sprite polarity paradox raised by Williams et al. (2007a); Williams et al. (2012) suggested that this paradox could be resolved by the numerous events missed by the conventional frame-rate video cameras, while their analysis also indicates that halo evens observed by the ISUAL satellite are mostly distributed in tropical areas. In particular, negative sprites appear to dominate in the Caribbean Sea, which needs to be validated through ground-based observations from the coastal regions nearby.

For sprites produced by positive strokes, the median and mean iCMCs (+347 and $+281 \mathrm{C} \mathrm{km}$, respectively) associated with ISUAL events are about half of that (-691 and $-644 \mathrm{C} \mathrm{km}$, respectively) related to negative sprites observed by both ISUAL and ground-based platforms. For the negative sprites, the statistics of parent strokes is similar to that associated with cases observed from the ground-based platform in the United States (e.g., Taylor et al. 2008; Li et al. 2012). The parent strokes of negative sprites are characterized by relatively high peak currents (at least $-75 \mathrm{kA}$ in our dataset and more than $-80 \mathrm{kA}$ in $>95 \%$ cases) and substantial impulse charge moment changes (more than $-300 \mathrm{C} \mathrm{km}$ in $>90 \%$ cases). More efforts will be made to compare the intensity of positive CG strokes associated with ISUAL sprites and ground-based observations of sprites.

In summary, our analysis suggests a distinct difference in the strength (in terms of impulse charge transfer by negative CG strokes) of lightning produced by continental and oceanic thunderstorms (e.g., Said et al. 2013; Zheng et al. 2016). The survey with Extremely Low-Frequency (ELF) electromagnetic radiation by Füllekrug et al. (2002) also indicates that particularly strong negative strokes with

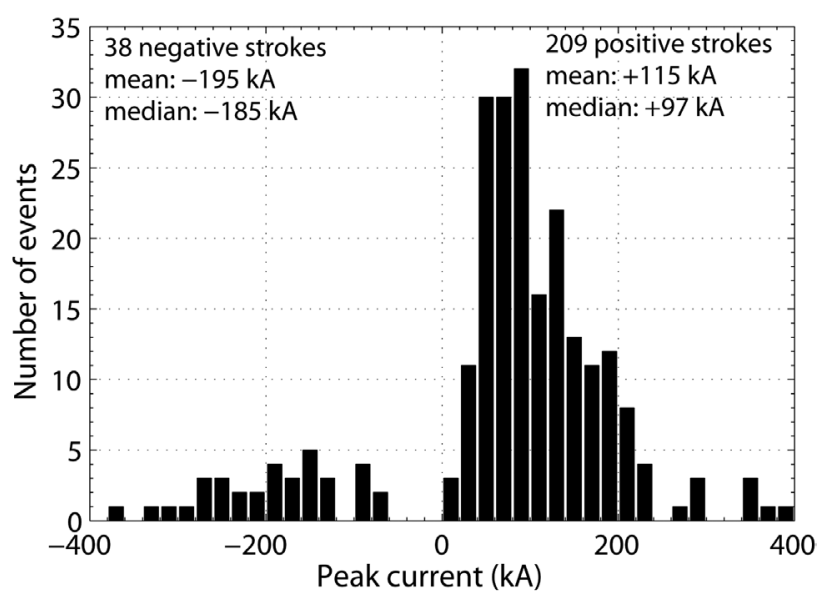

Fig. 8. Histogram of peak currents in 20-kA bin for causative cloud-toground (CG) strokes associated with 247 sprites observed by ISUAL. 
charge moment changes $>2000 \mathrm{C} \mathrm{km}$ occur mostly over oceans. Chronis et al. (2016) suggested that the relatively high strength of CG strokes over oceans is attributable to the enhanced potential of thunderstorms there. The observed dominance of negative sprites in some coastal areas near the tropics merits further investigation including ground-based observations from adjacent coast and a survey of lightning properties in this area. Moreover, it is worthwhile to confirm whether there is a significant population of negative sprites over oceanic thunderstorms. Further space-borne observations of sprites, in coordination with the ground-based networks of low-light-level cameras and broadband sferic sensors, are desired to investigate the difference between continental and oceanic thunderstorms in sprite production (Füllekrug et al. 2002). More efforts are necessary to reveal the difference between intense lightning strokes produced by continental and oceanic thunderstorms.

Acknowledgements The authors would thank Dr. Earle Williams and another anonymous reviewer for providing valuable comments on the paper. This work was supported jointly by National Key Basic Research and Development Program (2014CB441405), National Natural Science Foundation of China (No. 41574179), Open Research Program of Key Laboratory of Meteorological Disaster (Nanjing University of Information Science and Technology) of Ministry of Education (KLME1414), "The Hundred Talents Program" of Chinese Academy of Sciences (2013068), and Physical and Dynamic Meteorology Program of the United States National Science Foundation (NSF). The authors appreciate the contribution of Dr. Simon Huang, a previous PhD student in the National Cheng Kung University, at the very beginning of this work.

\section{REFERENCES}

Adachi, T., S. A. Cummer, J. Li, Y. Takahashi, R. R. Hsu, H. T. Su, A. B. Chen, S. B. Mende, and H. U. Frey, 2009: Estimating lightning current moment waveforms from satellite optical measurements. Geophys. Res. Lett., 36, L18808, doi: 10.1029/2009GL039911. [Link]

Barrington-Leigh, C. P., U. S. Inan, M. Stanley, and S. A. Cummer, 1999: Sprites triggered by negative lightning discharges. Geophys. Res. Lett., 26, 3605-3608, doi: 10.1029/1999GL010692. [Link]

Barrington-Leigh, C. P., U. S. Inan, and M. Stanley, 2001: Identification of sprites and elves with intensified video and broadband array photometry. J. Geophys. Res., 106, 1741-1750, doi: 10.1029/2000JA000073. [Link]

Biagi, C. J., K. L. Cummins, K. E. Kehoe, and E. P. Krider, 2007: National Lightning Detection Network (NLDN) performance in southern Arizona, Texas, and Oklahoma in 2003-2004. J. Geophys. Res., 112, D05208, doi: 10.1029/2006JD007341. [Link]
Boccippio, D. J., E. R. Williams, S. J. Heckman, W. A. Lyons, I. T. Baker, and R. Boldi, 1995: Sprites, ELF transients, and positive ground strokes. Science, 269, 10881091, doi: 10.1126/science.269.5227.1088. [Link]

Boggs, L. D., N. Liu, M. Splitt, S. Lazarus, C. Glenn, H. Rassoul, and S. A. Cummer, 2016: An analysis of five negative sprite-parent discharges and their associated thunderstorm charge structures. J. Geophys. Res., 121, 759-784, doi: 10.1002/2015JD024188. [Link]

Chen, A. B., C. L. Kuo, Y. J. Lee, H. T. Su, R. R. Hsu, J. L. Chern, H. U. Frey, S. B. Mende, Y. Takahashi, H. Fukunishi, Y. S. Chang, T. Y. Liu, and L. C. Lee, 2008: Global distributions and occurrence rates of transient luminous events. J. Geophys. Res., 113, A08306, doi: 10.1029/2008JA013101. [Link]

Chern, J. L., R. R. Hsu, H. T. Su, S. B. Mende, H. Fukunishi, Y. Takahashi, and L. C. Lee, 2003: Global survey of upper atmospheric transient luminous events on the ROCSAT-2 satellite. J. Atmos. Sol.-Terr. Phys., 65, 647-659, doi: 10.1016/S1364-6826(02)00317-6. [Link]

Chronis, T., W. Koshak, and E. McCaul, 2016: Why do oceanic negative cloud-to-ground lightning exhibit larger peak current values? J. Geophys. Res., 121, 4049-4068, doi: 10.1002/2015JD024129. [Link]

Cummer, S. A. and U. S. Inan, 2000: Modeling ELF radio atmospheric propagation and extracting lightning currents from ELF observations. Radio Sci., 35, 385-394, doi: 10.1029/1999RS002184. [Link]

Cummer, S. A. and W. A. Lyons, 2004: Lightning charge moment changes in U.S. High Plains thunderstorms. Geophys. Res. Lett., 31, L05114, doi: 10.1029/2003GL019043. [Link]

Cummer, S. A. and W. A. Lyons, 2005: Implications of lightning charge moment changes for sprite initiation.J.Geophys. Res., 110, A04304, doi: 10.1029/2004JA010812. [Link]

Cummer, S. A., U. S. Inan, T. F. Bell, and C. P. BarringtonLeigh, 1998: ELF radiation produced by electrical currents in sprites. Geophys. Res. Lett., 25, 1281-1284, doi: 10.1029/98GL50937. [Link]

Cummer, S. A., W. A. Lyons, and M. A. Stanley, 2013: Three years of lightning impulse charge moment change measurements in the United States. J. Geophys. Res., 118, 5176-5189, doi: 10.1002/jgrd .50442. [Link]

Cummins, K. L. and M. J. Murphy, 2009: An overview of lightning locating systems: History, techniques, and data uses, with an in-depth look at the U.S. NLDN. IEEE Trans. EMC, 51, 499-518, doi: 10.1109/ TEMC.2009.2023450. [Link]

Cummins, K. L., M. J. Murphy, E. A. Bardo, W. L. Hiscox, R. B. Pyle, and A. E. Pifer, 1998: A combined TOA/ MDF technology upgrade of the U.S. National Lightning Detection Network. J. Geophys. Res., 103, 90359044, doi: 10.1029/98JD00153. [Link] 
Dowden, R. L., J. B. Brundell, and C. J. Rodger, 2002: VLF lightning location by time of group arrival (TOGA) at multiple sites. J. Atmos. Sol.-Terr. Phys., 64, 817-830, doi: 10.1016/S1364-6826(02)00085-8. [Link]

Franz, R. C., R. J. Nemzek, and J. R. Winckler, 1990: Television image of a large upward electrical discharge above a thunderstorm system. Science, 249, 48-51, doi: 10.1126/science. 249.4964.48. [Link]

Füllekrug, M., D. R. Moudry, G. Dawes, and D. D. Sentman, 2001: Mesospheric sprite current triangulation. J. Geophys. Res., 106, 20189-20194, doi: 10.1029/2001JD900075. [Link]

Füllekrug, M., C. Price, Y. Yair, and E. R. Williams, 2002: Intense oceanic lightning. Ann. Geophys., 20, 133-137, doi: 10.5194/angeo-20-133-2002. [Link]

Gomes, C. and V. Cooray, 1998: Long impulse currents associated with positive return strokes. J. Atmos. Sol.-Terr. Phys., 60, 693-699, doi: 10.1016/s13646826(98)00039-x. [Link]

Hiraki,Y.,2010: Phase transition theory of sprite halo.J.Geophys. Res., 115, A00E20, doi: 10.1029/2009JA014384. [Link]

Hiraki, Y. and H. Fukunishi, 2006: Theoretical criterion of charge moment change by lightning for initiation of sprites. J. Geophys. Res., 111, A11305, doi: 10.1029/2006JA011729. [Link]

Hobara, Y., M. Hayakawa, E. Williams, R. Boldi, and E. Downes, 2006: Location and electrical properties of sprite-producing lightning from a single ELF site. In: Füllekrug, M., E. A. Mareev, and M. J. Rycroft (Eds.), Sprites, Elves and Intense Lightning Discharges, NATO Science Series II: Mathematics, Physics and Chemistry, 225, 211-235, Springer, Netherlands, doi: 10.1007/1-4020-4629-4_10. [Link]

Hu, W., S. A. Cummer, W. A. Lyons, and T. E. Nelson, 2002: Lightning charge moment changes for the initiation of sprites. Geophys. Res. Lett., 29, 1279, doi: 10.1029/2001GL014593. [Link]

Huang, E., E. Williams, R. Boldi, S. Heckman, W. Lyons, M. Taylor, T. Nelson, and C. Wong, 1999: Criteria for sprites and elves based on Schumann resonance observations. J. Geophys. Res., 104, 16943-16964, doi: 10.1029/1999JD900139. [Link]

Jehl, A., T. Farges, and E. Blanc, 2013: Color pictures of sprites from non-dedicated observation on board the International Space Station. J. Geophys. Res., 118, 454-461, doi: 10.1029/2012JA018144. [Link]

Kuo, C. L., R. R. Hsu, A. B. Chen, H. T. Su, L. C. Lee, S. B. Mende, H. U. Frey, H. Fukunishi, and Y. Takahashi, 2005: Electric fields and electron energies inferred from the ISUAL recorded sprites. Geophys. Res. Lett., 32, L19103, doi: 10.1029/2005gl023389. [Link]

Lang, T. J., S. A. Cummer, S. A. Rutledge, and W. A. Lyons, 2013: The meteorology of negative cloud-to-ground lightning strokes with large charge moment changes: Implications for negative sprites. J. Geophys. Res., 118, 7886-7896, doi: 10.1002/jgrd.50595. [Link]

Li, J., S. A. Cummer, W. A. Lyons, and T. E. Nelson, 2008: Coordinated analysis of delayed sprites with high-speed images and remote electromagnetic fields. J. Geophys. Res., 113, D20206, doi: 10.1029/2008JD010008. [Link]

Li, J., S. Cummer, G. Lu, and L. Zigoneanu, 2012: Charge moment change and lightning-driven electric fields associated with negative sprites and halos. J. Geophys. Res., 117, A09310, doi: 10.1029/2012JA017731. [Link]

Lu, G., S. A. Cummer, J. Li, F. Han, R. J. Blakeslee, and H. J. Christian, 2009: Charge transfer and in-cloud structure of large-charge-moment positive lightning strokes in a mesoscale convective system. Geophys. Res. Lett., 36, L15805, doi: 10.1029/2009GL038880. [Link]

Lu, G., S. A. Cummer, J. Li, F. Han, D. M. Smith, and B. W. Grefenstette, 2011: Characteristics of broadband lightning emissions associated with terrestrial gamma ray flashes. J. Geophys. Res., 116, A03316, doi: 10.1029/2010JA016141. [Link]

Lu, G., S. A. Cummer, R. J. Blakeslee, S. Weiss, and W. H. Beasley, 2012: Lightning morphology and impulse charge moment change of high peak current negative strokes. J. Geophys. Res., 117, D04212, doi: 10.1029/2011JD016890. [Link]

Lu, G., S. A. Cummer, J. Li, L. Zigoneanu, W. A. Lyons, M. A. Stanley, W. Rison, P. R. Krehbiel, H. E. Edens, R. J. Thomas, W. H. Beasley, S. A. Weiss, R. J. Blakeslee, E. C. Bruning, D. R. MacGorman, T. C. Meyer, K. Palivec, T. Ashcraft, and T. Samaras, 2013: Coordinated observations of sprites and in-cloud lightning flash structure. J. Geophys. Res., 118, 6607-6632, doi: 10.1002/jgrd.50459. [Link]

Lu, G., S. A. Cummer, Y. Tian, H. Zhang, F. Lyu, T. Wang, M. A. Stanley, J. Yang, and W. A. Lyons, 2016: Sprite produced by consecutive impulse charge transfers following a negative stroke: observation and simulation. J. Geophys. Res., 121, 4082-4092, doi: 10.1002/2015JD024644. [Link]

Lyons, W. A., 1996: Sprite observations above the U.S. High Plains in relation to their parent thunderstorm systems. J. Geophys. Res., 101, 29641-29652, doi: 10.1029/96JD01866. [Link]

Mende, S. B., H. U. Frey, R. R. Hsu, H. T. Su, A. B. Chen, L. C. Lee, D. D. Sentman, Y. Takahashi, and H. Fukunishi, 2005: $D$ region ionization by lightning-induced electromagnetic pulses. J. Geophys. Res., 110, A11312, doi: 10.1029/2005JA011064. [Link]

Miyasato, R., M. J. Taylor, H. Fukunishi, and H. C. Stenbaek-Nielsen, 2002: Statistical characteristics of sprite halo events using coincident photometric and imaging data. Geophys. Res. Lett., 29, 2033, doi: 10.1029/2001GL014480. [Link] 
Nag, A., S. Mallick, V. A. Rakov, J. S. Howard, C. J. Biagi, J. D. Hill, M. A. Uman, D. M. Jordan, K. J. Rambo, J. E. Jerauld, B. A. DeCarlo, K. L. Cummins, and J. A. Cramer, 2011: Evaluation of U.S. National Lightning Detection Network performance characteristics using rocket-triggered lightning data acquired in 2004-2009. J. Geophys. Res., 116, D02123, doi: 10.1029/2010JD014929. [Link]

Pasko, V. P. and H. C. Stenbaek-Nielsen, 2002: Diffuse and streamer regions of sprites. Geophys. Res. Lett., 29, doi: 10.1029/2001GL014241. [Link]

Pasko, V. P., U. S. Inan, T. F. Bell, and S. C. Reising, 1998: Mechanism of ELF radiation from sprites. Geophys. Res. Lett., 25, 3493-3496, doi: 10.1029/98GL02631. [Link]

Pasko, V. P., U. S. Inan, and T. F. Bell, 2000: Fractal structure of sprites. Geophys. Res. Lett., 27, 497-500, doi: 10.1029/1999g1010749. [Link]

Pessi, A. T., S. Businger, K. L. Cummins, N. W. S. Demetriades, M. Murphy, and B. Pifer, 2009: Development of a long-range lightning detection network for the Pacific: Construction, calibration, and performance. J. Atmos. Ocean. Technol., 26, 145-166, doi: 10.1175/2008JTECHA1132.1. [Link]

Qin, J., S. Celestin, and V. P. Pasko, 2011: On the inception of streamers from sprite halo events produced by lightning discharges with positive and negative polarity. J. Geophys. Res., 116, A06305, doi: 10.1029/2010JA016366. [Link]

Qin, J., S. Celestin, and V. P. Pasko, 2012: Minimum charge moment change in positive and negative cloud to ground lightning discharges producing sprites. Geophys. Res. Lett., 39, L22801, doi: 10.1029/2012GL053951. [Link]

Qin, J., S. Celestin, and V. P. Pasko, 2013: Dependence of positive and negative sprite morphology on lightning characteristics and upper atmospheric ambient conditions. J. Geophys. Res., 118, 2623-2638, doi: 10.1029/2012JA017908. [Link]

Reising, S. C., U. S. Inan, T. F. Bell, and W. A. Lyons, 1996: Evidence for continuing current in sprite-producing cloud-to-ground lightning. Geophys. Res. Lett., 23, 3639-3642, doi: 10.1029/96GL03480. [Link]

Said, R. K., M. B. Cohen, and U. S. Inan, 2013: Highly intense lightning over the oceans: Estimated peak currents from global GLD360 observations. J. Geophys. Res., 118, 6905-6915, doi: 10.1002/jgrd.50508. [Link]

Sato, M. and H. Fukunishi, 2003: Global sprite occurrence locations and rates derived from triangulation of transient Schumann resonance events. Geophys. Res. Lett., 30, doi: 10.1029/2003GL017291. [Link]

Sato, M., T. Ushio, T. Morimoto, M. Kikuchi, H. Kikuchi, T. Adachi, M. Suzuki, A. Yamazaki, Y. Takahashi, U. Inan, I. Linscott, R. Ishida, Y. Sakamoto, K. Yoshida, Y. Hobara, T. Sano, T. Abe, M. Nakamura, H.
Oda, and Z. I. Kawasaki, 2015: Overview and early results of the Global Lightning and Sprite Measurements mission. J. Geophys. Res., 120, 3822-3851, doi: 10.1002/2014JD022428. [Link]

Stanley, M., M. Brook, P. Krehbiel, and S. A. Cummer, 2000: Detection of daytime sprites via a unique sprite ELF signature. Geophys. Res. Lett., 27, 871-874, doi: 10.1029/1999GL010769. [Link]

Su, H. T., R. R. Hsu, A. B. C. Chen, Y. J. Lee, and L. C. Lee, 2002: Observation of sprites over the Asian continent and over oceans around Taiwan. Geophys. Res. Lett., 29, doi: 10.1029/2001GL013737. [Link]

Taylor, M. J., M. A. Bailey, P. D. Pautet, S. A. Cummer, N. Jaugey, J. N. Thomas, N. N. Solorzano, F. Sao Sabbas, R. H. Holzworth, O. Pinto, and N. J. Schuch, 2008: Rare measurements of a sprite with halo event driven by a negative lightning discharge over Argentina. Geophys. Res. Lett., 35, L14812, doi: 10.1029/2008GL033984. [Link]

Wescott, E. M., H. C. Stenbaek-Nielsen, D. D. Sentman, M. J. Heavner, D. R. Moudry, and F. T. São Sabbas, 2001: Triangulation of sprites, associated halos and their possible relation to causative lightning and micrometeors. J. Geophys. Res., 106, 10467-10477, doi: 10.1029/2000JA000182. [Link]

Williams, E. R., E. Downes, R. Boldi, W. Lyons, and S. Heckman, 2007a: Polarity asymmetry of sprite-producing lightning: A paradox? Radio Sci., 42, RS2S17, doi: 10.1029/2006RS003488. [Link]

Williams, E. R., V. C. Mushtak, R. Boldi, R. L. Dowden, and Z.-I. Kawasaki, 2007b: Sprite lightning heard round the world by Schumann resonance methods. Radio Sci., 42, RS2S20, doi: 10.1029/2006RS003498. [Link]

Williams, E. R., C. L. Kuo, J. Bór, G. Sátori, R. Newsome, T. Adachi, R. Boldi, A. Chen, E. Downes, R. R. Hsu, W. Lyons, M. M. F. Saba, M. Taylor, and H. T. Su, 2012: Resolution of the sprite polarity paradox: The role of halos. Radio Sci., 47, RS2002, doi: 10.1029/2011RS004794. [Link]

Yair, Y., P. Israelevich, A. D. Devir, M. Moalem, C. Price, J. H. Joseph, Z. Levin, B. Ziv, A. Sternlieb, and A. Teller, 2004: New observations of sprites from the space shuttle. J. Geophys. Res., 109, D15201, doi: 10.1029/2003JD004497. [Link]

Yair, Y.,C.Price, D. Katzenelson, N. Rosenthal,L. Rubanenko, Y. Ben-Ami, and E. Arnone, 2015: Sprite climatology in the Eastern Mediterranean Region. Atmos. Res., 157, 108-118, doi: 10.1016/j.atmosres.2014.12.018. [Link]

Zheng, D., Y. Zhang, Q. Meng, L. Chen, and J. Dan, 2016: Climatological comparison of small- and large-current cloud-to-ground lightning flashes over Southern China. J. Climate, 29, 2831-2848, doi: 10.1175/JCLID-15-0386.1. [Link] 